\title{
Antibiotic prophylaxis and risk of Clostridium difficile infection after coronary artery bypass graft surgery
}

\author{
Jashvant Poeran, MD, PhD, ${ }^{\mathrm{a}}$ Madhu Mazumdar, $\mathrm{PhD},{ }^{\mathrm{a}}$ Rehana Rasul, MA, MPH, ${ }^{\mathrm{a}}$ \\ Joanne Meyer, MS, PharmD, ${ }^{\mathrm{b}}$ Henry S. Sacks, MD, PhD,${ }^{\mathrm{c}}$ Brian S. Koll, MD, ${ }^{\mathrm{c}, \mathrm{d}}$ Frances R. Wallach, MD, ${ }^{\mathrm{c}, \mathrm{d}}$ \\ Alan Moskowitz, MD, ${ }^{e}$ and Annetine C. Gelijns, $\mathrm{PhD}^{\mathrm{e}}$
}

\begin{abstract}
Objective: Antibiotic use, particularly type and duration, is a crucial modifiable risk factor for Clostridium difficile. Cardiac surgery is of particular interest because prophylactic antibiotics are recommended for 48 hours or less (vs $\leq 24$ hours for noncardiac surgery), with increasing vancomycin use. We aimed to study associations between antibiotic prophylaxis (duration/vancomycin use) and $C$ difficile among patients undergoing coronary artery bypass grafting.
\end{abstract}

Methods: We extracted data on coronary artery bypass grafting procedures from the national Premier Perspective claims database (2006-2013, $n=154,200,233$ hospitals). Multilevel multivariable logistic regressions measured associations between (1) duration ( $<2$ days, "standard" vs $\geq 2$ days, "extended") and (2) type of antibiotic used ("cephalosporin," "cephalosporin + vancomycin," "vancomycin") and $C$ difficile as outcome.

Results: Overall $C$ difficile prevalence was $0.21 \%(\mathrm{n}=329)$. Most patients $(59.7 \%)$ received a cephalosporin only; in $33.1 \%$ vancomycin was added, whereas $7.2 \%$ received vancomycin only. Extended prophylaxis was used in $20.9 \%$. In adjusted analyses, extended prophylaxis (vs standard) was associated with significantly increased $C$ difficile risk (odds ratio, 1.43; confidence interval, 1.07-1.92), whereas no significant associations existed for vancomycin use as adjuvant or primary prophylactic compared with the use of cephalosporins (odds ratio, 1.21; confidence interval, 0.92-1.60, and odds ratio, 1.39; confidence interval, 0.94-2.05, respectively). Substantial inter-hospital variation exists in the percentage of extended antibiotic prophylaxis (interquartile range, 2.5-35.7), use of adjuvant vancomycin (interquartile range, 4.2-61.1), and vancomycin alone (interquartile range, 2.3-10.4).

Conclusions: Although extended use of antibiotic prophylaxis was associated with increased $C$ difficile risk after coronary artery bypass grafting, vancomycin use was not. The observed hospital variation in antibiotic prophylaxis practices suggests great potential for efforts aimed at standardizing practices that subsequently could reduce $C$ difficile risk. (J Thorac Cardiovasc Surg 2016;151:589-97)

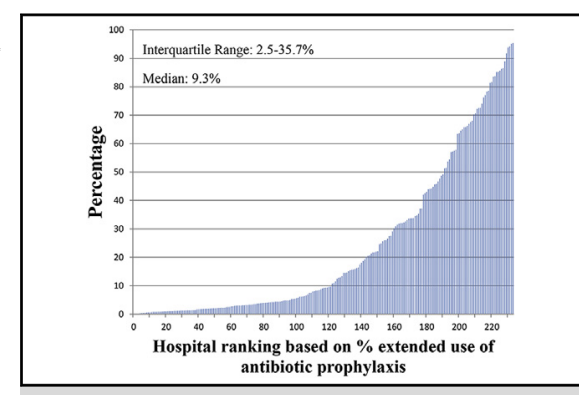

There is substantial hospital variation in antibiotic prophylaxis more than 48 hours in patients undergoing CABG.

\section{Central Message}

Although extended use of antibiotic prophylaxis was associated with increased $C$ difficile risk after $\mathrm{CABG}$ surgery, vancomycin use was not.

\section{Perspective}

In patients undergoing CABG, extended antibiotic prophylaxis was associated with increased $C$ difficile risks with substantial inter-hospital variation in antibiotic prophylaxis characteristics. Current patient safety and financial stakes combined with possible future reimbursement penalties demand prioritization of this issue and effective strategies to decrease $C$ difficile.

See Editorial Commentary page 598.

\footnotetext{
From the ${ }^{\mathrm{a}}$ Department of Population Health Science and Policy, Institute for Healthcare Delivery Science, Icahn School of Medicine at Mount Sinai, New York, NY; ${ }^{\mathrm{b}}$ Department of Pharmacy, The Mount Sinai Hospital, New York, NY; ${ }^{\mathrm{c}}$ Icahn School of Medicine at Mount Sinai, New York, NY; ${ }^{\mathrm{d}}$ Infection Prevention and Control, Mount Sinai Health System, New York, NY; ${ }^{\text {e}}$ Department of Population Health Science and Policy, Icahn School of Medicine at Mount Sinai, New York, NY.

M.M., A.M., and A.C.G. are partially funded by Cardiothoracic Surgical Trials Network (http://www.ctsurgerynet.org/). Institutional Review Board approval was obtained (project HS\#: 14-00647).
}

Received for publication Nov 18, 2014; revisions received Sept 17, 2015; accepted for publication Sept 22, 2015; available ahead of print Nov 4, 2015

Address for reprints: Jashvant Poeran, MD, PhD, Department of Population Health Science \& Policy, Institute for Healthcare Delivery Science, Icahn School of Medicine at Mount Sinai, 1425 Madison Ave (Box 1077), New York, NY 10029 (E-mail: jashvant.poeran@mountsinai.org). $0022-5223 / \$ 36.00$

Copyright (c) 2016 by The American Association for Thoracic Surgery http://dx.doi.org/10.1016/j.jtcvs.2015.09.090 


\begin{tabular}{|c|c|}
\hline \multicolumn{2}{|c|}{ Abbreviations and Acronyms } \\
\hline $\mathrm{CABG}$ & $=$ coronary artery bypass grafting \\
\hline CI & $=$ confidence interval \\
\hline CMS & $\begin{aligned}= & \text { Centers for Medicare \& Medicaid } \\
& \text { Services }\end{aligned}$ \\
\hline ICD-9 & $\begin{aligned}= & \text { International Classification of } \\
& \text { Diseases-9th revision [Clinical } \\
& \text { Modification] }\end{aligned}$ \\
\hline IQR & $=$ interquartile range \\
\hline OR & $=$ odds ratio \\
\hline SCIP & $=$ Surgical Care Improvement Project \\
\hline
\end{tabular}

Of Supplemental material is available online.

Clostridium difficile infections are an increasing problem in hospitalized patients, currently affecting more than 300,000 hospitalizations annually in the United States. ${ }^{1}$ The development of $C$ difficile compromises patient safety ${ }^{2}$ and increases length of hospital stay and costs of hospitalization, with overall cost estimates of $C$ difficile of up to $\$ 3.2$ billion per year. $^{3-5}$ Antibiotic use is regarded as a crucial modifiable risk factor for $C$ difficile, with studies demonstrating increased risks associated with the extended use of antibiotics, number of antibiotics used, and use of cephalosporins, clindamycin, and fluoroquinolones in particular. $^{6-8}$ Because prophylactic antibiotics are routinely administered to patients undergoing surgery, characteristics of this practice provide an important target to explore in efforts to reduce $C$ difficile. Of particular interest are patients undergoing cardiac surgery because they differ from those undergoing general surgery regarding, for example, the use of cardiopulmonary bypass, hypothermia, the length of surgery, or indwelling chest catheters after surgery., Therefore, several guidelines (eg, Society of Thoracic Surgeons) recommend 48 hours or less for antibiotic prophylaxis compared with 24 hours or less for noncardiac surgery. ${ }^{10-13} \mathrm{~A}$ cephalosporin (usually cefazolin) is recommended as the antibiotic of choice; vancomycin is recommended as an adjuvant or the primary prophylactic antibiotic in a high-risk case for staphylococcal infection or $\beta$-lactam/penicillin allergy, respectively. ${ }^{14}$ However, concerns have been raised on the effect of both the longer duration of prophylaxis and the increasing use of vancomycin on the risk for resistant organisms and $C$ difficile. ${ }^{15,16}$ Moreover, $C$ difficile has recently been found to be one of the main infections after cardiac surgery and is increasingly recognized as an important contributor to morbidity and mortality in this patient group. ${ }^{5,17}$
By using a nationwide claims-based database, we therefore sought to study the association between characteristics of antibiotic prophylaxis and $C$ difficile in patients undergoing coronary artery bypass grafting (CABG) surgery with or without valve repair/replacement. The specific characteristics of interest were the extended use of prophylactic antibiotics ( $\geq 2$ days after surgery) and the use of vancomycin as an adjuvant to cephalosporins or as the primary prophylactic antibiotic. We hypothesized both characteristics to be associated with an increased risk for $C$ difficile in patients undergoing $\mathrm{CABG}$.

\section{MATERIALS AND METHODS \\ Data Source and Study Design}

For this retrospective study, we used data from the Premier Perspective database $^{18}$ (Premier Inc, Charlotte, NC) containing surgical hospital discharges from January 2006 to December 2013. This database contains complete billing information on a patient's hospitalization. Apart from International Classification of Diseases-9th revision Clinical Modification (ICD-9 CM) codes and Current Procedural Terminology codes, this claims-based dataset provides standardized billing items. Up to 30 ICD-9 $\mathrm{CM}$ codes can be recorded for each hospitalization. Before data are incorporated in the Premier database, the vendor performs a rigorous data validation and quality assurance process. This process involves a 7-step integrity analysis, followed by approximately 150 sampling and statistical validity and integrity assurance crosschecks on all hospitalsupplied data. For standardized codes, such as ICD-9 and Current Procedural Terminology codes, the codes are ascertained to be valid for the time period the patient record is reported. The dataset is increasingly used by a variety of study groups addressing clinical questions. ${ }^{19,20}$ These data meet the requirements of de-identification as defined by the Health Insurance Portability and Accountability Act and were exempt from consent requirements of the Mount Sinai Medical Center Institutional Review Board (project HS\#: 14-00,647).

\section{Study Sample}

The cohort contained CABG procedures (with or without valve repair/ replacement) performed from 2006 to 2013 indicated by ICD-9 CM code 36.1 (including subcodes). Exclusion criteria were based on previous studies. ${ }^{8,16}$ We excluded cases with unknown gender or discharge type $(\mathrm{n}=602)$, systemic antibiotic use before surgery $(\mathrm{n}=87,407)$, no billing for antibiotic use on the day of surgery $(17,031)$, a switch in antibiotic class or gaps in antibiotic use of 1 or more days (to distinguish between treatment and prophylaxis, $\mathrm{n}=55,958$ ), and patients who died, developed $C$ difficile, or were discharged within 2 days after surgery $(\mathrm{n}=1466)$, the minimum plausible induction time for $C$ difficile to be associated with the studied exposure. ${ }^{21}$ Finally, we also excluded patients who were billed for prophylactic antibiotics other than cephalosporins or vancomycin $(n=4357)$. In particular, the exclusion of patients who died within 2 days was applied to keep our cohort strategy similar to a comparable study ${ }^{16}$ that studied the association between adjuvant vancomycin and $C$ difficile risk in patients undergoing CABG. The main rationale is that these patients were not at risk of developing $C$ difficile because 2 days is the minimum plausible induction time. To have a sufficient sample size per cluster, we also included only hospitals with more than $50 \mathrm{CABG}$ procedures. ${ }^{22}$

\section{Study Variables}

The main exposures of interest were the extended use of prophylactic antibiotics and the use of vancomycin as an adjuvant to cephalosporins or the primary prophylactic antibiotic. Prophylactic antibiotic use was 
categorized into parenteral use of a cephalosporin only, a cephalosporin and vancomycin, or vancomycin only. Use was defined as billing for prophylaxis on the day of surgery or both the day of surgery and the day after (standard) versus billing for prophylaxis up to day 2 after surgery or later (extended).

Patient demographics included age, gender, and race (white, black, other). Healthcare-related variables included transfer from another hospital, type of insurance (commercial, Medicaid, Medicare, uninsured, other), hospital teaching status, and the mean annual number of CABG surgeries per hospital. Procedure-related variables included the day of procedure (as a measure of preoperative stay), the number of grafts involved (1- $\leq 4)$, concomitant valve repair/replacement, use of an internal thoracic artery graft, previous CABG surgery, emergency admission, and year of procedure. Variables related to comorbidity burden were Quan and colleagues, ${ }^{23}$ update of the Deyo adaptation of the Charlson comorbidities and index, and the use of antacid medications (proton pump inhibitors and $\mathrm{H} 2$ receptor antagonists) because these medications have been associated with increased $C$ difficile risk. $^{24}$

The main outcome, $C$ difficile 48 hours or more postoperatively, was defined as the presence of all of the following criteria ${ }^{16}$ : (1) having an ICD-9 code 008.45, (2) billing for a stool study for $C$ difficile, and (3) billing for $C$ difficile therapy, that is, intravenous or oral metronidazole or oral vancomycin 2 days or more after surgery.

\section{Statistical Analysis}

The univariable association between extended antibiotic use and study variables was assessed using chi-square tests and $t$ tests for categoric and continuous variables, respectively. To demonstrate potential inter-hospital variability, the percentage (y-axis) of (1) extended antibiotic use, (2) adjuvant vancomycin use, and (3) just vancomycin use by hospital (x-axis) was illustrated on separate graphs.

A multilevel multivariable logistic regression was then performed to measure the association among extended antibiotic use, vancomycin use, and $C$ difficile. It included a random intercept term that varies at the level of each hospital and accounts for correlation of patients within hospitals. The model was adjusted using all variables found significant at the $P$ less than .15 level from the univariable tests and had at least 10 cases within each category. Adjusted odds ratio (OR), 95\% confidence interval (CI), and $P$ value are reported and to be used together as a measure of overall significance. Hospital variation in $C$ difficile was measured using the intraclass correlation coefficient of the final model. Model discrimination was evaluated using the $\mathrm{C}$-statistic.

Similar to others, we chose to use a conservative measure of $C$ difficile defined by 3 criteria. ${ }^{16}$ However, numerous studies often have relied only on ICD-9 coding because a high sensitivity $(71 \%)$ and specificity (99\%) for $C$ difficile have been demonstrated. ${ }^{25,26}$ Therefore, we assessed sensitivity to the definition of $C$ difficile diagnosis by repeating the model with $C$ difficile defined as just the presence of ICD-9 code 008.45 , irrespective of a stool sample or antibiotic therapy indication.

\section{RESULTS}

The final study sample consisted of 154,200 CABG surgeries performed in 233 hospitals (Figure 1).

\section{Characteristics}

Overall, 92,013 (59.7\%; range, 0-100) of patients received a cephalosporin only as prophylaxis; in 51,109 patients $(33.1 \%$; range, $0-100)$, vancomycin was added, and in 11,078 patients ( $7.2 \%$; range, $0-82.6)$, vancomycin was used as the primary prophylactic. Extended prophylaxis was used in $32,291(20.9 \%$; range, $0-95.4)$ cases.

Table 1 provides a breakdown of the characteristics of antibiotic prophylaxis, patient demographics, healthcarerelated variables, and procedure-related variables by standard versus extended antibiotic prophylaxis. Although statistically significant, there were no major differences between the standard group and the extended antibiotic prophylaxis group. Most notable (comparing standard vs extended antibiotic prophylaxis), mean age differed only slightly (65.4 vs 65.7 years), as did the mean DeyoCharlson comorbidity index $(0.96$ vs 0.93$)$ (both $P<.01$ ). Appendix E1 provides more insight into the distribution of $C$ difficile by the study variables. Appendix E2 provides the separate Deyo-Charlson comorbidities by standard versus extended antibiotic prophylaxis.

\section{Univariable and Multivariable Clostridium difficile Risk}

Overall, $C$ difficile was observed in 329 patients $(0.21 \%)$ with great hospital-level variation (range, $0-2$; interquartile range $[\mathrm{IQR}], 0.1-0.3)$. Those who received extended antibiotic prophylaxis (compared with standard prophylaxis) had a higher $C$ difficile prevalence: $0.30 \%$ versus $0.19 \%$, respectively $(P<.01)$ (Table 2$)$. When looking at type of antibiotic prophylaxis, higher $C$ difficile risks were observed for adjuvant vancomycin $(0.25 \%)$ and vancomycin only $(0.33 \%)$ compared with the use of cephalosporins $(0.18 \%)(P<.01)$.

After adjustment for relevant covariates (Table 3), the association with increased $C$ difficile risk remained: extended prophylaxis (vs standard) (OR, 1.43; CI, 1.07-1.92). However, there was no significant association between $C$ difficile and vancomycin use as adjuvant or alone (compared with the use of cephalosporins) (OR, 1.21; CI 0.92-1.60, and OR, 1.39; CI, 0.94-2.05, respectively).

The results were comparable when using a less-restrictive definition of $C$ difficile ( $\mathrm{n}=398$, overall prevalence $0.26 \%$ ). The model's c-statistic was 0.76 for the main model and 0.75 for the sensitivity analysis. The intraclass correlation coefficient of the final model was $15.1 \%$ depicting the proportion of variation between hospitals that explains the outcome of $C$ difficile.

To assess the potential effect of missing data on our multivariable results, we also studied the $C$ difficile rates in 2 excluded groups: (1) those with unknown gender or discharge type ( $\mathrm{n}=602$; no $C$ difficile cases) and (2) those who were not billed for antibiotics on the day of surgery ( $\mathrm{n}=17,031 ; C$ difficile rate $0.56 \%$ ). Because the latter is higher than the $C$ difficile rate found in the study cohort $(0.21 \%)$, the exclusion might have led to a bias of our effect estimates toward the null, meaning that our results could be an underestimation of the actual effect. 


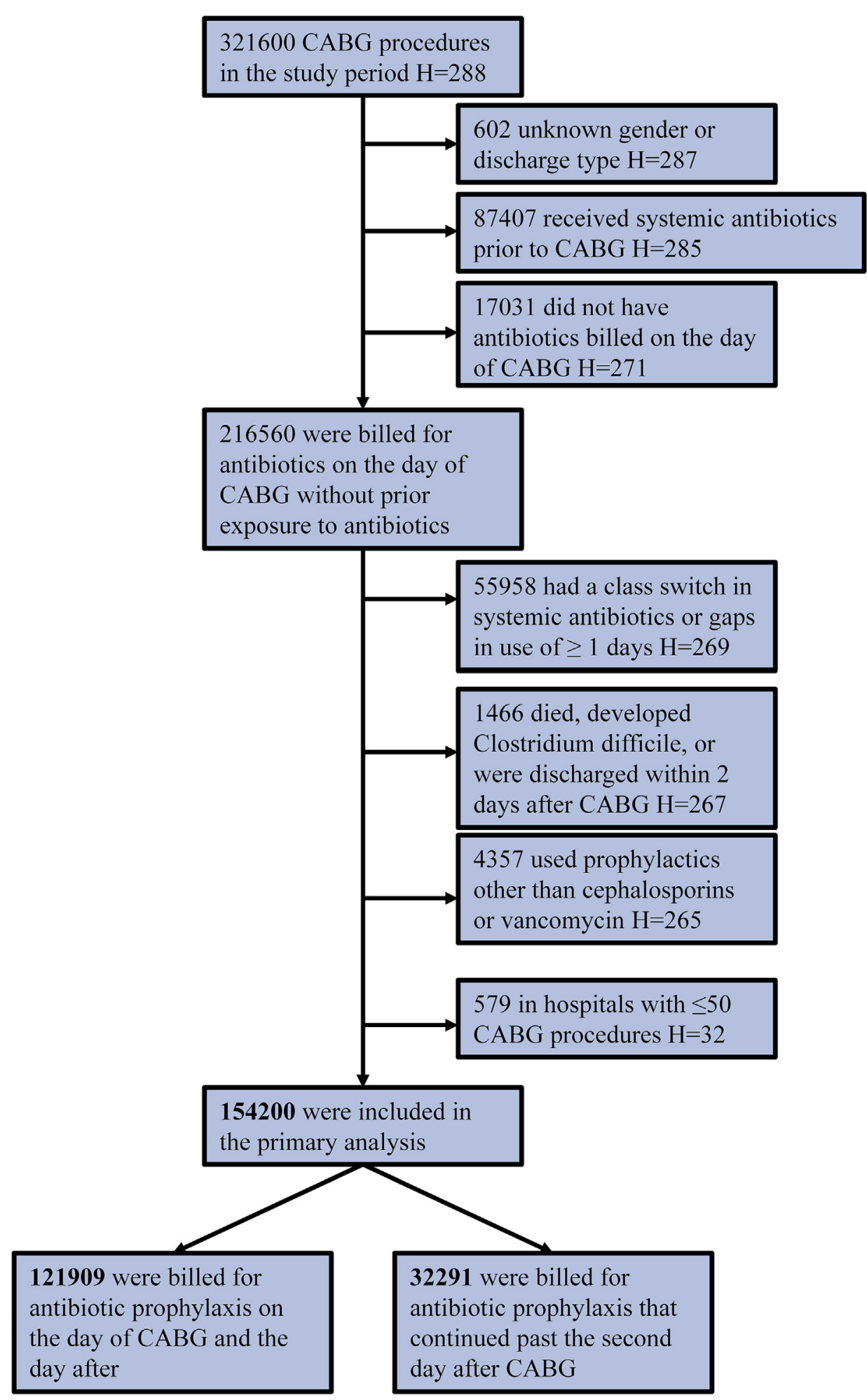

FIGURE 1. Patient flow chart.* *Patients may belong to more than 1 exclusion criteria in each step. " $\mathrm{H}$ " stands for the number of hospitals; because exclusions are on the patient level, the number of hospitals mentioned in each step does not reflect the number of hospitals excluded. In any of the exclusion steps, no complete hospitals (ie, all CABG cases in those hospitals) are excluded. $C A B G$, Coronary artery bypass grafting. 
TABLE 1. Patient demographics, healthcare related, procedure related, and comorbidity variables by standard versus extended use of antibiotic prophylaxis

\begin{tabular}{|c|c|c|c|c|c|}
\hline \multirow[b]{3}{*}{ Characteristics } & \multicolumn{4}{|c|}{ Antibiotic prophylaxis } & \multirow{3}{*}{$\begin{array}{c}P \\
\text { value }\end{array}$} \\
\hline & \multicolumn{2}{|c|}{ Standard } & \multicolumn{2}{|c|}{ Extended } & \\
\hline & $\mathbf{N}^{*}$ & $\% *$ & $\mathbf{N}^{*}$ & $\% *$ & \\
\hline \multicolumn{6}{|l|}{ Antibiotic prophylaxis group } \\
\hline Cephalosporin only & 71,934 & 59.0 & 20,079 & 62.2 & $<.01$ \\
\hline $\begin{array}{l}\text { Cephalosporin with } \\
\text { Vancomycin }\end{array}$ & 40,357 & 33.1 & 10,752 & 33.3 & \\
\hline Vancomycin only & 9618 & 7.9 & 1460 & 4.5 & \\
\hline \multicolumn{6}{|l|}{ Patient demographics } \\
\hline Age continuous* & 65.4 & 10.6 & 65.7 & 10.8 & $<.01$ \\
\hline \multicolumn{6}{|l|}{ Age category } \\
\hline$<45$ y & 3449 & 2.8 & 924 & 2.9 & $<.01$ \\
\hline $45-54$ y & 16,155 & 13.3 & 4112 & 12.7 & \\
\hline $55-64$ y & 35,541 & 29.2 & 9232 & 28.6 & \\
\hline $65-74$ y & 40,217 & 33.0 & 10,633 & 32.9 & \\
\hline$>75 \mathrm{y}$ & 26,547 & 21.8 & 7390 & 22.9 & \\
\hline \multicolumn{6}{|l|}{ Gender } \\
\hline Female & 30,681 & 25.2 & 8027 & 24.9 & .25 \\
\hline Male & 91,228 & 74.8 & 24,264 & 75.1 & \\
\hline \multicolumn{6}{|l|}{ Race } \\
\hline White & 92,037 & 75.5 & 22,330 & 69.2 & $<.01$ \\
\hline Black & 7471 & 6.1 & 1782 & 5.5 & \\
\hline Other & 22,401 & 18.4 & 8179 & 25.3 & \\
\hline \multicolumn{6}{|l|}{ Healthcare related } \\
\hline $\begin{array}{l}\text { Transfer from other } \\
\text { hospital }\end{array}$ & 16,878 & 13.8 & 4750 & 14.7 & $<.01$ \\
\hline \multicolumn{6}{|l|}{ Insurance type } \\
\hline Commercial & 42,685 & 35.0 & 10,959 & 33.9 & $<.01$ \\
\hline Medicaid & 5831 & 4.8 & 1739 & 5.4 & \\
\hline Medicare & 65,238 & 53.5 & 17,497 & 54.2 & \\
\hline Uninsured/other & 8155 & 6.7 & 2096 & 6.5 & \\
\hline \multicolumn{6}{|l|}{ Hospital teaching status } \\
\hline Nonteaching & 54,998 & 45.1 & 15,334 & 47.5 & $<.01$ \\
\hline Teaching & 66,911 & 54.9 & 16,957 & 52.5 & \\
\hline $\begin{array}{l}\text { Mean annual no. of } \\
\text { CABGs per hospital* }\end{array}$ & 211 & 144 & 184 & 123 & $<.01$ \\
\hline \multicolumn{6}{|l|}{ Procedure related } \\
\hline Mean day of procedure & 1.6 & 2.2 & 1.6 & 2.2 & .97 \\
\hline 1 & 23,435 & 19.22 & 6519 & 20.19 & $<.01$ \\
\hline 2 & 42,651 & 34.99 & 11,456 & 35.48 & .10 \\
\hline 3 & 33,978 & 27.87 & 8861 & 27.44 & .12 \\
\hline$\geq 4$ & 14,958 & 12.27 & 3997 & 12.38 & .60 \\
\hline $\begin{array}{l}\text { Concomitant valve } \\
\text { repair/replacement }\end{array}$ & 16,892 & 13.86 & 4872 & 15.09 & $<.01$ \\
\hline ITA graft & 106,835 & 87.64 & 27,762 & 85.97 & $<.01$ \\
\hline Previous CABG surgery & 290 & 0.2 & 68 & 0.2 & .36 \\
\hline Emergency admission & 26,399 & 21.7 & 7448 & 23.1 & $<.01$ \\
\hline \multicolumn{6}{|l|}{ Year of procedure } \\
\hline 2006 & 16,108 & 13.2 & 4284 & 13.3 & $<.01$ \\
\hline 2007 & 16,362 & 13.4 & 4022 & 12.5 & \\
\hline 2008 & 14,308 & 11.7 & 3553 & 11.0 & \\
\hline 2009 & 16,119 & 13.2 & 3171 & 9.8 & \\
\hline 2010 & 16,244 & 13.3 & 3594 & 11.1 & \\
\hline
\end{tabular}

TABLE 1. Continued

\begin{tabular}{|c|c|c|c|c|c|}
\hline \multirow[b]{3}{*}{ Characteristics } & \multicolumn{4}{|c|}{ Antibiotic prophylaxis } & \multirow{3}{*}{$\begin{array}{c}P \\
\text { value } \dagger\end{array}$} \\
\hline & \multicolumn{2}{|c|}{ Standard } & \multicolumn{2}{|c|}{ Extended } & \\
\hline & $\mathbf{N}^{*}$ & $\% *$ & $\mathbf{N}^{*}$ & $\% *$ & \\
\hline 2011 & 15,186 & 12.5 & 3996 & 12.4 & \\
\hline 2011 & 14,677 & 12.0 & 4794 & 14.8 & \\
\hline 2013 & 12,905 & 10.6 & 4877 & 15.1 & \\
\hline \multicolumn{6}{|l|}{ Comorbidity burden } \\
\hline $\begin{array}{l}\text { Mean Deyo-Charlson } \\
\text { comorbidity index* }\end{array}$ & 0.96 & 1.33 & 0.93 & 1.30 & $<.01$ \\
\hline $\begin{array}{r}\text { Use of antacid } \\
\text { medications }\end{array}$ & 116,377 & 95.5 & 31,095 & 96.3 & $<.01$ \\
\hline
\end{tabular}

\section{Hospital Variation in Antibiotic Prophylaxis Characteristics}

Figures 2-4 show the extent of inter-hospital variation of the percentage of extended antibiotic prophylaxis use (IQR, 2.5-35.7), the percentage of adjuvant vancomycin (IQR, 4.2-61.1), and the percentage of vancomycin use as the primary prophylactic (IQR, 2.3-10.4), respectively. Appendix E3 provides a breakdown for these figures by hospital teaching status and hospital location (urban vs rural), showing no apparent differences between hospital types.

\section{DISCUSSION}

In this large population-based study using data from 154,200 patients who underwent CABG surgery in 233 hospitals, we found extended antibiotic prophylaxis to be associated with increased risks for $C$ difficile. On the basis of $C$ difficile definition, this increased risk ranged from $43 \%$ to $39 \%$. Conversely, the use of vancomycin, as the primary prophylactic or added to a cephalosporin, was not associated with an increased $C$ difficile risk. We further demonstrated substantial inter-hospital variation in antibiotic prophylaxis characteristics, which suggests great

TABLE 2. Extended antibiotic prophylaxis and type of antibiotic by Clostridium difficile occurrence

\begin{tabular}{|c|c|c|c|c|}
\hline \multirow[b]{3}{*}{ Characteristics } & \multicolumn{3}{|c|}{ C difficile } & \multirow[b]{3}{*}{$P$ value* } \\
\hline & \multirow{2}{*}{$\begin{array}{c}\text { No } \\
\mathbf{N}\end{array}$} & \multicolumn{2}{|c|}{ Yes } & \\
\hline & & $\mathbf{N}$ & $\%$ & \\
\hline \multicolumn{5}{|l|}{ Duration of antibiotic prophylaxis } \\
\hline Extended & 32,193 & 98 & 0.30 & $<.01$ \\
\hline Standard & 121,678 & 231 & 0.19 & \\
\hline \multicolumn{5}{|l|}{ Type of antibiotic prophylaxis } \\
\hline Cephalosporin only & 91,848 & 165 & 0.18 & $<.01$ \\
\hline Cephalosporin with Vancomycin & 50,982 & 127 & 0.25 & \\
\hline Vancomycin only & 11,041 & 37 & 0.33 & \\
\hline
\end{tabular}


TABLE 3. Adjusted* association between antibiotic prophylaxis measures and Clostridium difficile

\begin{tabular}{|c|c|c|}
\hline & \multicolumn{2}{|c|}{ Definition of Clostridium difficile } \\
\hline & Restrictive & $\begin{array}{c}\text { Less restrictive } \\
\text { (sensitivity analysis) }\end{array}$ \\
\hline & OR* $(95 \%$ CI $)$ & OR* $(95 \%$ CI $)$ \\
\hline \multicolumn{3}{|c|}{ Extended antibiotic prophylaxis } \\
\hline No & Reference & Reference \\
\hline Yes & $1.43(1.07-1.92)$ & $1.39(1.08-1.82)$ \\
\hline \multicolumn{3}{|c|}{ Type of antibiotic prophylaxis } \\
\hline Cephalosporin only & Reference & Reference \\
\hline $\begin{array}{l}\text { Cephalosporin with } \\
\text { Vancomycin }\end{array}$ & $1.21(0.92-1.60)$ & $1.16(0.90-1.48)$ \\
\hline Vancomycin only & $1.39(0.94-2.05)$ & $1.37(0.96-1.95)$ \\
\hline \multicolumn{3}{|c|}{$\begin{array}{l}C I \text {, Confidence interval; } O R \text {, odds ratio. *Adjusted for age, race, transfer from another } \\
\text { hospital, insurance type, hospital teaching status, mean annual number of CABG sur- } \\
\text { geries per hospital, preoperative hospital stay, number of grafts, concomitant valve } \\
\text { repair/replacement, internal thoracic artery graft, emergency admission, year of } \\
\text { procedure, Deyo-Charlson comorbidities, use of antacid medications; all } P<.05 \text {. }\end{array}$} \\
\hline
\end{tabular}

potential for efforts aimed at standardizing these practices, which subsequently could reduce $C$ difficile risks.

Several recent studies have emphasized the importance of $C$ difficile and its link to antibiotic prophylaxis in patients undergoing cardiac surgery. ${ }^{2,17,27}$ Traditionally, the prevention of surgical site infections is considered the main objective of antibiotic prophylaxis. However, a recent study shifted the focus to other infections after cardiac surgery. By using prospective and detailed data from more than 5000 patients, Gelijns and colleagues ${ }^{17}$ demonstrated the majority ( $79 \%$ ) of infections after cardiac surgery to be pneumonia, bloodstream infections, or $C$ difficile. Adding more priority to this topic are the current developments at the Centers for Medicare \& Medicaid Services (CMS). As of October 2008, the CMS does not reimburse care related to several so-called hospital-acquired conditions, including some infections. Although $C$ difficile infections have been considered, they have not yet been included in this list. ${ }^{28}$ However, as regular reevaluations have been announced, $C$ difficile infections might be included in the future, potentially resulting in a considerable financial burden for hospitals.

In this study, we focused on 2 characteristics that are perhaps the most important modifiable risk factors for $C$ difficile $^{6-8}$ : the extended use of prophylactic antibiotics and the type of antibiotic used for prophylaxis, in our study the use of vancomycin alone or as an adjuvant. Currently, extended use has a different definition in cardiac surgery than in noncardiac surgery: more than 48 hours versus more than 24 hours postoperatively, respectively. Two recent meta-analyses have focused on the question of optimal duration in light of surgical site infections after cardiac surgery. However, the trials that were included in these meta-analyses mostly did not report on adverse events such as resistant bacteria or $C$ difficile. ${ }^{9,29}$ Moreover, analysis of recent data has shown a similar postoperative infection risk for less than 24 hours compared with less than 48 hours of antibiotic prophylaxis. ${ }^{17}$ This underlines the need for additional

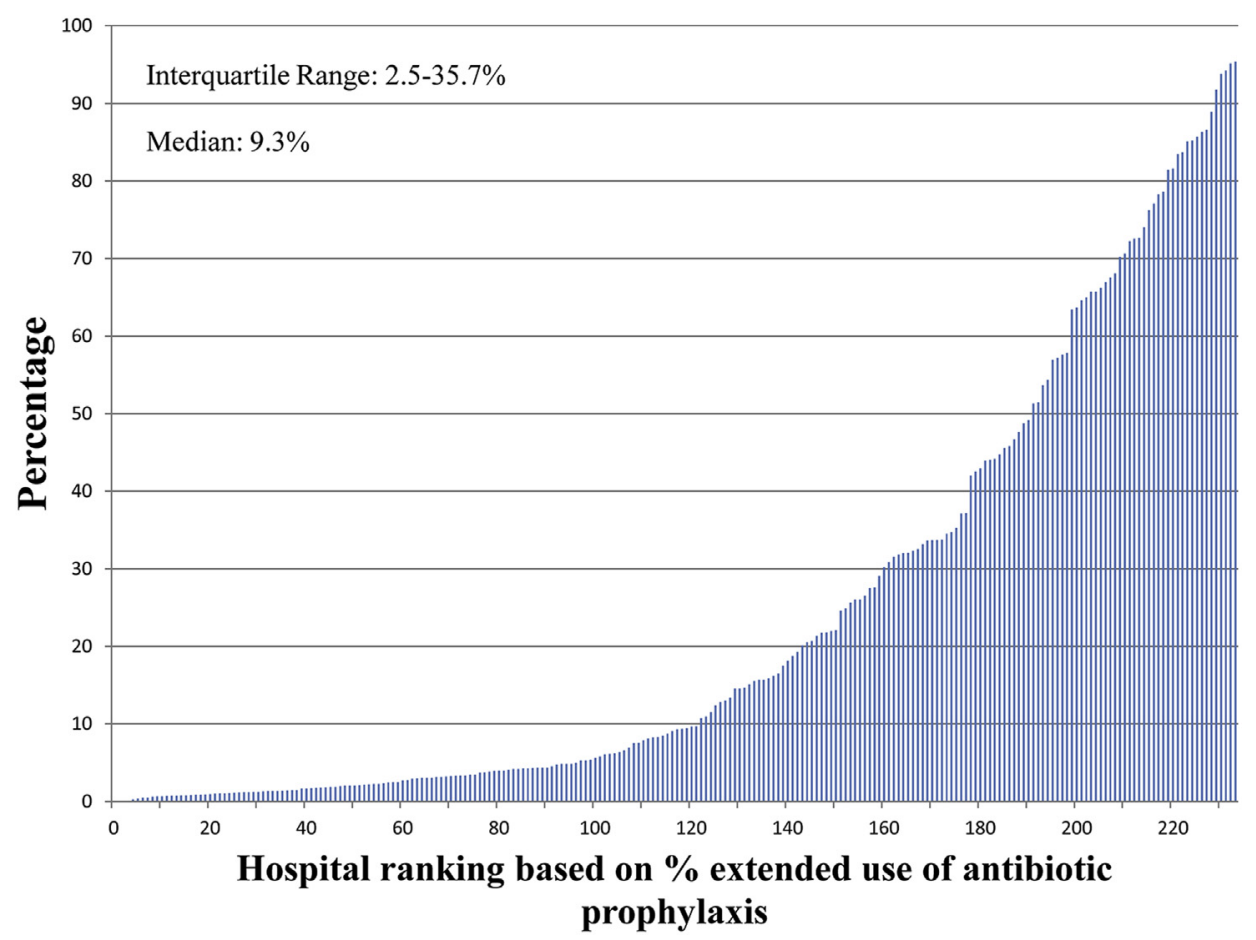

FIGURE 2. Percentage of CABG surgeries in which there is extended antibiotic prophylaxis, by hospital. 


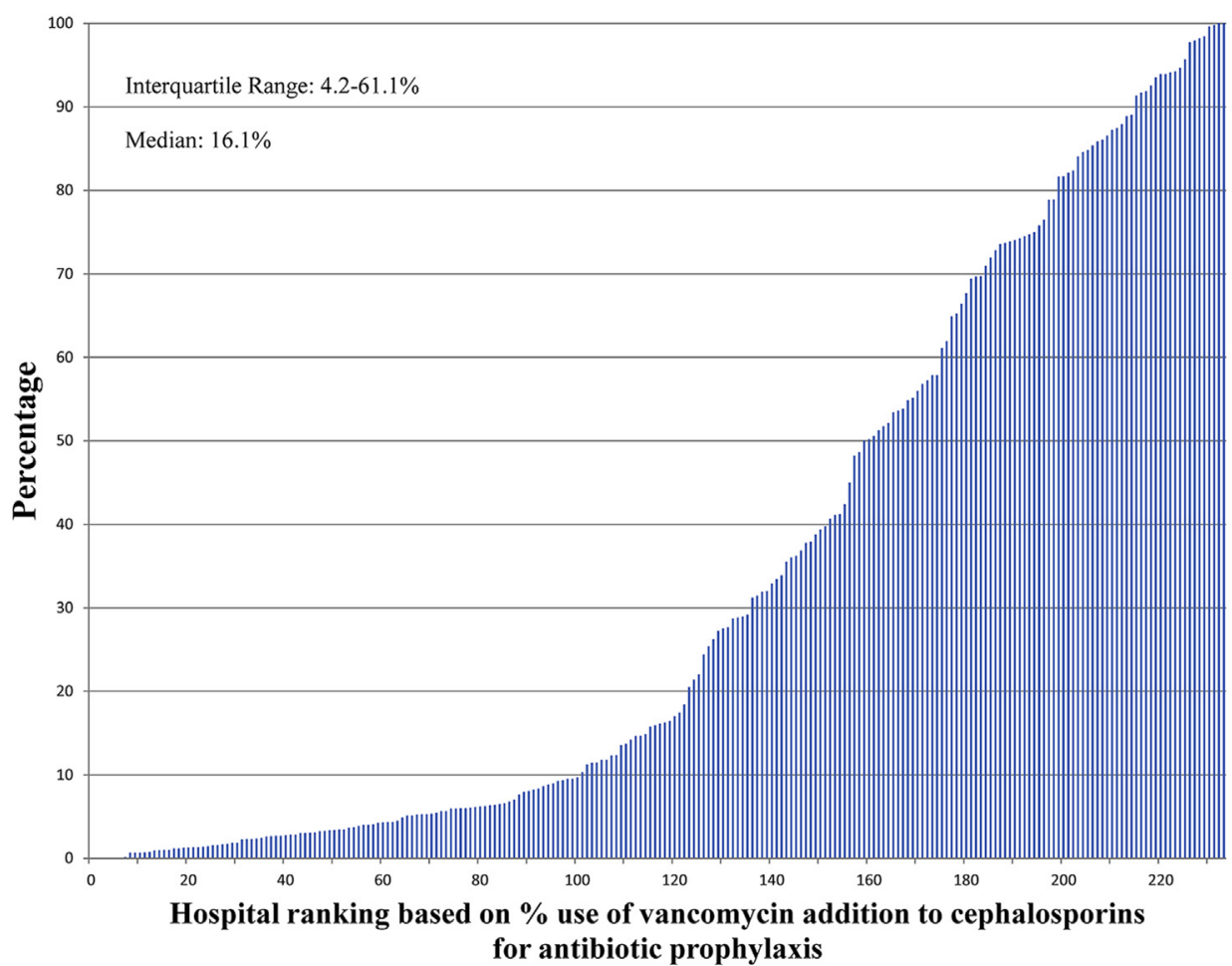

FIGURE 3. Percentage of CABG surgeries in which vancomycin is added to cephalosporins for antibiotic prophylaxis, by hospital.

studies, particularly those that assess effect on surgical site infections and adverse events.

Data on vancomycin as a risk factor for $C$ difficile are sparse, as are data on a potential mechanism of action. Although oral vancomycin is excreted in the stool and can serve as treatment of $C$ difficile, intravenous administration does not. Moreover, intravenous vancomycin has been linked to ecologic disturbances of the intestinal microflora predisposing $C$ difficile overgrowth..$^{21,30,31}$ Only 1 previous study has assessed the role of vancomycin addition to cephalosporins in $C$ difficile after cardiac surgery. ${ }^{16}$ The $C$ difficile prevalence in this

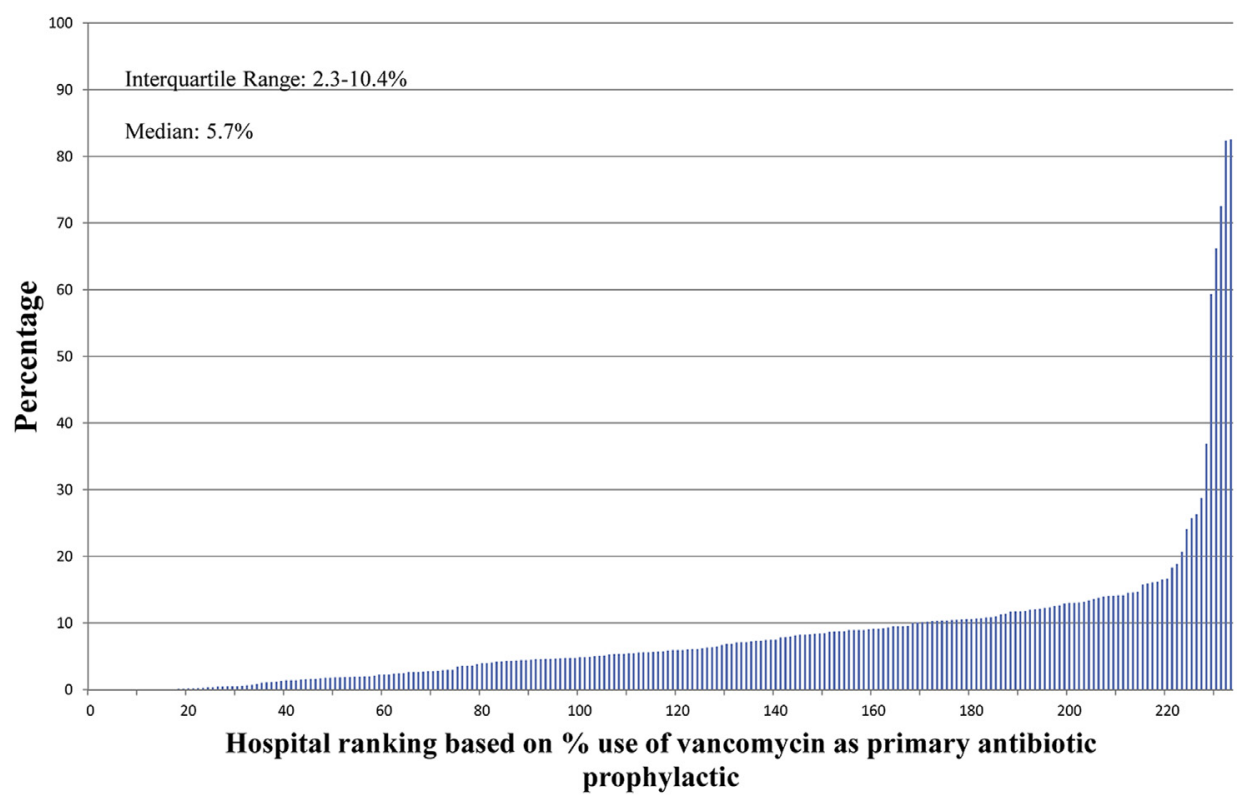

FIGURE 4. Percentage of CABG surgeries in which vancomycin is used as primary antibiotic prophylactic, by hospital. 
respective cohort of patients undergoing CABG was $0.4 \%$ $(\mathrm{n}=256)$. In line with our findings, the authors did not find an association between adjuvant vancomycin and $C$ difficile risk. Moreover, they used a propensity score analysis to adjust for confounding, whereas we have used a multilevel multivariable logistic regression approach. The fact that both strategies demonstrate no association of vancomycin use (while using similar definitions) with increased $C$ difficile risk adds to the robustness of this finding. Important future work could be aimed at (hospital-specific) factors affecting the choice of specific antibiotics as prophylaxis. Although guidelines specifically mention adjuvant vancomycin in case of high risk for staphylococcal infection, or vancomycin as primary prophylactic antibiotic in $\beta$-lactam/penicillin-allergic patients, additional data on the rationale for antibiotic choice seem imperative. ${ }^{10-12,14}$ Moreover, guidelines, however complete, may not always be applicable to every situation. White and colleagues ${ }^{27}$ have recently described their institutional transition from cephalosporin-based antimicrobial prophylaxis for cardiac surgery to flucloxacillin (or teicoplanin) and gentamicin after several apparent prophylaxis failures, continued institutional presence of methicillin-resistant staphylococcus aureus, and ongoing problems with $C$ difficile. They found their practice change to have decreased $C$ difficile without changing the incidence of wound infections or renal complications. ${ }^{27}$

Inter-hospital variation in antibiotic prophylaxis practices has been described for several procedures, including cardiac surgery. ${ }^{17,32}$ The significant variation demonstrated in the current study suggests great potential for efforts such as Surgical Care Improvement Project (SCIP), a collaboration between the CMS and the Centers for Disease Control and Prevention to improve and standardize surgical care by a set of measures eventually reducing surgical complications, including surgical site infections. ${ }^{33}$ A number of studies have assessed the impact of SCIP on outcomes, including surgical infections in mostly noncardiac surgery, however, with mixed results. $^{34,35}$ Although several SCIP measures have been retired recently (January 2015), continuing evaluation of practice standardization and outcomes and implementation barriers of SCIP measures will be crucial in its success.

\section{Study Limitations}

The main limitation of our study is the lack of detailed clinical information in the billing dataset used; data are collected for the purpose of billing, not research. This limitation particularly pertains to the indications for the billed antibiotics for which we cannot distinguish between prophylaxis and treatment in case of extended use or if there were any particular reasons to use vancomycin; this might have resulted in indication bias. In addition, what is captured in billing databases does not necessarily reflect what is actually administered to the patient because there might be a mismatch between the two. We have tried to account for this by limiting our dataset to patients with antibiotic use starting on the day of surgery and excluding combinations of antibiotic use (except for vancomycin combined with cephalosporins). Moreover, we expect the effect of the mismatch to be minimal because our study objective focused on daily use without going into details on dosages. Another limitation, partly referring to the lack of clinical information, pertains to the definition of $C$. difficile from billing data for the inpatient period only. The latter seems particularly important because a substantial proportion $(45 \%)$ of infections after cardiac surgery (including $C$ difficile) occur after hospital discharge. ${ }^{17}$ Although the effect of this limitation theoretically could go in both directions, we believe, on the basis of the described effects of antibiotic use on $C$ difficile, ${ }^{6-8}$ that it results in an underestimation of the effect of extended antibiotic prophylaxis on $C$ difficile. Several other mechanisms also emphasize the conservative measure of our effect estimates. The excluded group of patients with no billing for antibiotics on the day of surgery $(\mathrm{n}=17,031)$ (Figure 1$)$ had a higher $C$ difficile rate than our study cohort $(0.56 \%$ vs $0.21 \%$, respectively); the same was true for the group of patients using prophylactic antibiotics other than those used in the study ( $\mathrm{n}=4357 ; C$ difficile rate $2.6 \%$ ). Moreover, we used a restrictive $C$ difficile definition as previously described $^{16}$ and found the same results when using a more inclusive ICD-9 only definition, illustrating the robustness of our findings. Adding to this, but also illustrating the heterogeneity in populations, our $C$ difficile prevalence estimates are comparable to some ${ }^{27}$ but not other studies demonstrating higher prevalences. ${ }^{5,17}$ Given the limitations pertaining to the use of billing data to answer clinical questions, we believe that our study provides some useful insights. Important next steps are additional retrospective studies looking into the effect of antibiotic prophylaxis on $C$ difficile risk in other procedures and using other data sources. Furthermore, well-designed prospective studies would shed additional light on this important clinical question, which would also benefit from a (multicenter) clinical registry in which all variables of interest geared toward this question (eg, exact timing and duration of prophylaxis) are captured. A study geared toward prophylaxis patterns and the incidence of all postoperative infections would be needed to consider actual changes in antibiotic guidelines. The objective would be to weigh the risk of particularly $C$ difficile and resistant organisms against infections (eg, mediastinitis) that might be positively affected by a longer duration of prophylaxis or the use of vancomycin. Theoretically, reducing postoperative mediastinitis with a longer duration of antibiotic prophylaxis at the expense of more $C$ difficile may be completely justified. 


\section{CONCLUSIONS}

With the use of billing data from 154,200 patients who underwent $\mathrm{CABG}$, we found extended antibiotic prophylaxis to be associated with increased risks for $C$ difficile, whereas the use of vancomycin was not. Substantial inter-hospital variation in antibiotic prophylaxis characteristics suggests great potential for efforts aimed at standardizing these practices, which could subsequently reduce $C$ difficile risks. Current patient safety and financial stakes combined with possible future reimbursement penalties demand prioritization of this issue and effective strategies to decrease $C$ difficile.

\section{Conflict of Interest Statement}

Authors have nothing to disclose with regard to commercial support.

\section{References}

1. Lucado J, Gould C, Elixhauser A. Agency for Healthcare Research and Quality. Statistical Brief \#124 Clostridium difficile infections (CDI) in hospital stays, 2009. Available at: http://www.hcup-us.ahrq.gov/reports/statbriefs/sb124.pdf. Accessed August 18, 2014.

2. Crabtree T, Aitchison D, Meyers BF, Tymkew H, Smith JR, Guthrie TJ, et al. Clostridium difficile in cardiac surgery: risk factors and impact on postoperative outcome. Ann Thorac Surg. 2007;83:1396-402.

3. O'Brien JA, Lahue BJ, Caro JJ, Davidson DM. The emerging infectious challenge of clostridium difficile-associated disease in Massachusetts hospitals: clinical and economic consequences. Infect Control Hosp Epidemiol. 2007;28: 1219-27.

4. Gabriel L, Beriot-Mathiot A. Hospitalization stay and costs attributable to Clostridium difficile infection: a critical review. J Hosp Infect. 2014;88:12-21.

5. Keshavamurthy S, Koch CG, Fraser TG, Gordon SM, Houghtaling PL, Soltesz EG, et al. Clostridium difficile infection after cardiac surgery: Prevalence, morbidity, mortality, and resource utilization. J Thorac Cardiovasc Surg. 2014;148:3157-65.

6. Owens RC Jr, Donskey CJ, Gaynes RP, Loo VG, Muto CA. Antimicrobialassociated risk factors for Clostridium difficile infection. Clin Infect Dis. 2008;46(Suppl 1):S19-31.

7. Slimings C, Riley TV. Antibiotics and hospital-acquired Clostridium difficile infection: update of systematic review and meta-analysis. J Antimicrob Chemother. 2014;69:881-91.

8. Calvert JK, Holt SK, Mossanen M, James AC, Wright JL, Porter MP, et al. Use and outcomes of extended antibiotic prophylaxis in urological cancer surgery. J Urol. 2014;192:425-9.

9. Mertz D, Johnstone J, Loeb M. Does duration of perioperative antibiotic prophylaxis matter in cardiac surgery? A systematic review and meta-analysis. Ann Surg. 2011;254:48-54.

10. The Joint Commission. Specifications Manual for National Hospital Inpatient Quality Measures; Discharges 01-01-14 through 12-31-14. Surgical Care Improvement Project National Hospital Inpatient Quality Measures. Available at: http://www.jointcommission.org/specifications_manual_for_national_ hospital_inpatient_quality_measures.aspx. Accessed August 19, 2014.

11. Antimicrobial prophylaxis for surgery. Treat Guidel Med Letter. 2012;10:73-8. quiz 79-80.

12. Bratzler DW, Dellinger EP, Olsen KM, Perl TM, Auwaerter PG, Bolon MK, et al. Clinical practice guidelines for antimicrobial prophylaxis in surgery. Surg Infect (Larchmt). 2013;14:73-156.

13. Edwards FH, Engelman RM, Houck P, Shahian DM, Bridges CR, Society of Thoracic Surgeons. The Society of Thoracic Surgeons practice guideline series: antibiotic prophylaxis in cardiac surgery, part I: duration. Ann Thorac Surg. 2006; 81:397-404.

14. Engelman R, Shahian D, Shemin R, Guy TS, Bratzler D, Edwards F, et al. The Society of Thoracic Surgeons practice guideline series: Antibiotic prophy- laxis in cardiac surgery, part II: Antibiotic choice. Ann Thorac Surg. 2007;83: 1569-76.

15. Levine DP. Vancomycin: a history. Clin Infect Dis. 2006;42(Suppl 1):S5-12.

16. Bateman BT, Rassen JA, Schneeweiss S, Bykov K, Franklin JM, Gagne JJ, et al. Adjuvant vancomycin for antibiotic prophylaxis and risk of Clostridium difficile infection after coronary artery bypass graft surgery. J Thorac Cardiovasc Surg. 2013;146:472-8

17. Gelijns AC, Moskowitz AJ, Acker MA, Argenziano M, Geller NL, Puskas JD et al. Management practices and major infections after cardiac surgery. J Am Coll Cardiol. 2014;64:372-81.

18. Premier Inc. Premier Perspective Database. Available at: https://www. premierinc.com/transforming-healthcare/healthcare-performance-improvement/ premier-research-services. Accessed May 25, 2015.

19. Dharmarajan K, Strait KM, Lagu T, Lindenauer PK, Tinetti ME, Lynn J, et al. Acute decompensated heart failure is routinely treated as a cardiopulmonary syndrome. PLoS One. 2013;8:e78222.

20. Safavi KC, Dharmarajan K, Kim N, Strait KM, Li SX, Chen SI, et al. Variation exists in rates of admission to intensive care units for heart failure patients across hospitals in the United States. Circulation. 2013;127:923-9.

21. Dubberke ER, Reske KA, Yan Y, Olsen MA, McDonald LC, Fraser VJ. Clostridium difficile-associated disease in a setting of endemicity: identification of novel risk factors. Clin Infect Dis. 2007;45:1543-9.

22. Moineddin R, Matheson FI, Glazier RH. A simulation study of sample size for multilevel logistic regression models. BMC Med Res Methodol. 2007; $7: 34$.

23. Quan H, Sundararajan V, Halfon P, Fong A, Burnand B, Luthi JC, et al. Coding algorithms for defining comorbidities in ICD-9-CM and ICD-10 administrative data. Med Care. 2005;43:1130-9.

24. Janarthanan S, Ditah I, Adler DG, Ehrinpreis MN. Clostridium difficileassociated diarrhea and proton pump inhibitor therapy: a meta-analysis. Am J Gastroenterol. 2012;107:1001-10.

25. Scheurer DB, Hicks LS, Cook EF, Schnipper JL. Accuracy of ICD-9 coding for Clostridium difficile infections: a retrospective cohort. Epidemiol Infect. 2007; 135:1010-3

26. Collins CE, Ayturk MD, Flahive JM, Emhoff TA, Anderson FA Jr, Santry HP. Epidemiology and outcomes of community-acquired Clostridium difficile infections in Medicare beneficiaries. J Am Coll Surg. 2014;218:1141-7.e1.

27. White RW, West R, Howard P, Sandoe J. Antimicrobial regime for cardiac surgery: the safety and effectiveness of short-course flucloxacillin (or teicoplanin) and gentamicin-based prophylaxis. J Cardiovasc Surg. 2013;28: 512-6.

28. Centers for Medicare \& Medicaid Services. Press release: CMS proposes to expand quality program for hospital inpatient services in FY 2009. Available at: http://www.cms.gov/Newsroom/MediaReleaseDatabase/Press-releases/ 2008-Press-releases-items/2008-04-14.html. Accessed August 19, 2014.

29. Lador A, Nasir H, Mansur N, Sharoni E, Biderman P, Leibovici L, et al. Antibiotic prophylaxis in cardiac surgery: systematic review and meta-analysis. J Antimicrob Chemother. 2012;67:541-50.

30. Rafii F, Sutherland JB, Cerniglia CE. Effects of treatment with antimicrobial agents on the human colonic microflora. Ther Clin Risk Manag. 2008;4:1343-58.

31. Stevens V, Dumyati G, Fine LS, Fisher SG, van Wijngaarden E. Cumulative antibiotic exposures over time and the risk of Clostridium difficile infection. Clin Infect Dis. 2011;53:42-8.

32. Beckmann A, Doebler K, Schaefer E, Koetting J, Gastmeier P, Graf K. Sternal surgical site infection prevention - is there any room for improvement? Eur $J$ Cardiothorac Surg. 2011;40:347-51.

33. Bratzler DW, Hunt DR. The surgical infection prevention and surgical care improvement projects: national initiatives to improve outcomes for patient having surgery. Clin Infect Dis. 2006;43:322-30.

34. Rasouli MR, Jaberi MM, Hozack WJ, Parvizi J, Rothman RH. Surgical care improvement project (SCIP): has its mission succeeded? J Arthroplasty. 2013; 28:1072-5.

35. Stulberg JJ, Delaney CP, Neuhauser DV, Aron DC, Fu P, Koroukian SM Adherence to surgical care improvement project measures and the association with postoperative infections. JAMA. 2010;303:2479-85.

Key Words: Clostridium difficile, coronary artery bypass graft, antibiotic prophylaxis, vancomycin 
APPENDIX E1. Patient demographics, healthcare related, procedure related, and comorbidity variables by yes or no for Clostridium difficile

\begin{tabular}{|c|c|c|c|c|c|}
\hline \multirow[b]{3}{*}{ Characteristics } & \multicolumn{4}{|c|}{ C difficile } & \multirow{3}{*}{$\begin{array}{c}P \\
\text { value }\end{array}$} \\
\hline & \multicolumn{2}{|l|}{ No } & \multicolumn{2}{|c|}{ Yes } & \\
\hline & $\mathbf{N}^{*}$ & $\% *$ & $\mathbf{N} *$ & $\% *$ & \\
\hline \multicolumn{6}{|l|}{ Antibiotic prophylaxis } \\
\hline \multicolumn{6}{|l|}{ Duration } \\
\hline Extended & 122,124 & 79.1 & 234 & 69.9 & $<.01$ \\
\hline Standard & 32,320 & 20.9 & 101 & 30.1 & \\
\hline \multicolumn{6}{|l|}{ Type of antibiotic } \\
\hline Cephalosporin only & 92,146 & 59.7 & 168 & 50.1 & $<.01$ \\
\hline $\begin{array}{l}\text { Cephalosporin with } \\
\text { vancomycin }\end{array}$ & 51,187 & 33.1 & 130 & 38.8 & \\
\hline Vancomycin only & 11,111 & 7.2 & 37 & 11.0 & \\
\hline \multicolumn{6}{|l|}{ Patient demographics } \\
\hline Age continuous* & 65.4 & 10.7 & 70.2 & 10.8 & $<.01$ \\
\hline \multicolumn{6}{|l|}{ Age category } \\
\hline$<45 \mathrm{y}$ & 4394 & 2.8 & 7 & 2.1 & $<.01$ \\
\hline $45-54$ y & 20,324 & 13.2 & 24 & 7.2 & \\
\hline $55-64$ y & 44,879 & 29.1 & 60 & 17.9 & \\
\hline $65-74$ y & 50,942 & 33.0 & 111 & 33.1 & \\
\hline$>75 \mathrm{y}$ & 33,905 & 22.0 & 133 & 39.7 & \\
\hline \multicolumn{6}{|l|}{ Gender } \\
\hline Female & 38,736 & 25.1 & 125 & 37.3 & $<.01$ \\
\hline Male & 115,708 & 74.9 & 210 & 62.7 & \\
\hline \multicolumn{6}{|l|}{ Race } \\
\hline White & 114,474 & 74.1 & 251 & 74.9 & .88 \\
\hline Black & 9258 & 6.0 & 18 & 5.4 & \\
\hline Other & 30,712 & 19.9 & 66 & 19.7 & \\
\hline \multicolumn{6}{|l|}{ Healthcare related } \\
\hline $\begin{array}{l}\text { Transfer from other } \\
\text { hospital }\end{array}$ & 21,615 & 14.0 & 70 & 20.9 & $<.01$ \\
\hline \multicolumn{6}{|l|}{ Insurance type } \\
\hline Commercial & 53,784 & 34.8 & 59 & 17.6 & $<.01$ \\
\hline Medicaid & 7589 & 4.9 & 21 & 6.3 & \\
\hline Medicare & 82,795 & 53.6 & 243 & 72.5 & \\
\hline Uninsured/other & 10,276 & 6.7 & 12 & 3.6 & \\
\hline \multicolumn{6}{|l|}{ Hospital teaching status } \\
\hline Nonteaching & 70,640 & 45.7 & 160 & 47.8 & .46 \\
\hline Teaching & 83,804 & 54.3 & 175 & 52.2 & \\
\hline $\begin{array}{l}\text { Mean annual no. of } \\
\text { CABGs per hospital* }\end{array}$ & 205 & 141 & 188 & 141 & .26 \\
\hline \multicolumn{6}{|l|}{ Procedure related } \\
\hline Mean day of procedure & 1.6 & 2.2 & 1.9 & 2.4 & $<.01$ \\
\hline \multicolumn{6}{|l|}{ No. of grafts } \\
\hline 1 & 30,002 & 19.4 & 73 & 21.8 & .27 \\
\hline 2 & 54,189 & 35.1 & 108 & 32.2 & .28 \\
\hline 3 & 42,914 & 27.8 & 88 & 26.3 & .54 \\
\hline$\geq 4$ & 18,979 & 12.3 & 51 & 15.2 & .10 \\
\hline $\begin{array}{l}\text { Concomitant valve } \\
\text { repair/replacement }\end{array}$ & 21,738 & 14.1 & 94 & 28.1 & $<.01$ \\
\hline ITA graft & 134,815 & 87.3 & 272 & 81.2 & $<.01$ \\
\hline Previous CABG surgery & 358 & 0.2 & 0 & 0.0 & .38 \\
\hline Emergency admission & 33,938 & 22.0 & 82 & 24.5 & .27 \\
\hline
\end{tabular}

APPENDIX E1. Continued

\begin{tabular}{|c|c|c|c|c|c|}
\hline \multirow[b]{3}{*}{ Characteristics } & \multicolumn{4}{|c|}{ C difficile } & \multirow{3}{*}{$\begin{array}{c}P \\
\text { value }\end{array}$} \\
\hline & \multicolumn{2}{|l|}{ No } & \multicolumn{2}{|c|}{ Yes } & \\
\hline & $\mathbf{N}^{*}$ & $\% *$ & $\mathbf{N}^{*}$ & $\% *$ & \\
\hline \multicolumn{6}{|l|}{ Year of procedure } \\
\hline 2006 & 20,406 & 13.2 & 49 & 14.6 & .24 \\
\hline 2007 & 20,376 & 13.2 & 50 & 14.9 & \\
\hline 2008 & 17,839 & 11.6 & 39 & 11.6 & \\
\hline 2009 & 19,262 & 12.5 & 51 & 15.2 & \\
\hline 2010 & 19,864 & 12.9 & 30 & 9.0 & \\
\hline 2011 & 19,261 & 12.5 & 33 & 9.9 & \\
\hline 2011 & 19,562 & 12.7 & 42 & 12.5 & \\
\hline 2013 & 17,874 & 11.6 & 41 & 12.2 & \\
\hline \multicolumn{6}{|l|}{ Comorbidity burden } \\
\hline $\begin{array}{r}\text { Mean Deyo-Charlson } \\
\text { comorbidity index* }\end{array}$ & 0.95 & 1.3 & 2.02 & 1.9 & $<.01$ \\
\hline Use of antacid medications & 147,661 & 95.6 & 324 & 96.7 & .32 \\
\hline \multicolumn{6}{|c|}{$\begin{array}{l}C A B G \text {, Coronary artery bypass grafting; ITA, internal thoracic artery. }{ }^{*} \text { Continuous } \\
\text { variable mean and standard deviation instead of } \mathrm{N} \text { and } \% \text {, respectively. } \dagger \text { Chi-square } \\
\text { test for categoric variables, } t \text { test for continuous variables. }\end{array}$} \\
\hline
\end{tabular}

APPENDIX E2. Deyo-Charlson comorbidities by standard versus extended use of antibiotic prophylaxis

\begin{tabular}{|c|c|c|c|c|c|}
\hline \multirow[b]{3}{*}{ Comorbidities } & \multicolumn{4}{|c|}{ Antibiotic prophylaxis } & \multirow{3}{*}{$\begin{array}{c}P \\
\text { value }\end{array}$} \\
\hline & \multicolumn{2}{|c|}{ Standard } & \multicolumn{2}{|c|}{ Extended } & \\
\hline & $\mathbf{N}$ & $\%$ & $\mathbf{N}$ & $\%$ & \\
\hline \multicolumn{6}{|c|}{ Deyo-Charlson comorbidity grouping } \\
\hline Myocardial infarction & 46,017 & 37.6 & 12,416 & 38.3 & .02 \\
\hline Congestive heart failure & 23,970 & 19.6 & 6622 & 20.4 & $<.01$ \\
\hline Peripheral vascular disease & 18,933 & 15.5 & 4648 & 14.3 & $<.01$ \\
\hline Cerebrovascular disease & 11,696 & 9.6 & 3033 & 9.4 & .27 \\
\hline Dementia & 359 & 0.3 & 89 & 0.3 & .57 \\
\hline Chronic pulmonary disease & 30,157 & 24.6 & 7226 & 22.3 & $<.01$ \\
\hline Rheumatologic disease & 2331 & 1.9 & 619 & 1.9 & .96 \\
\hline Peptic ulcer disease & 1800 & 1.5 & 451 & 1.4 & .28 \\
\hline Mild liver disease & 1844 & 1.5 & 492 & 1.5 & .89 \\
\hline Moderate/severe liver disease & 202 & 0.2 & 55 & 0.2 & .86 \\
\hline Diabetes & 44,951 & 36.7 & 12,272 & 37.9 & $<.01$ \\
\hline $\begin{array}{l}\text { Diabetes with chronic } \\
\text { complications }\end{array}$ & 6857 & 5.6 & 1591 & 4.9 & $<.01$ \\
\hline Hemiplegia or paraplegia & 589 & 0.5 & 185 & 0.6 & .04 \\
\hline Renal disease & 15,156 & 12.4 & 3677 & 11.3 & $<.01$ \\
\hline Any malignancy & 2983 & 2.4 & 758 & 2.3 & .30 \\
\hline Metastatic solid tumor & 316 & 0.3 & 63 & 0.2 & .04 \\
\hline
\end{tabular}




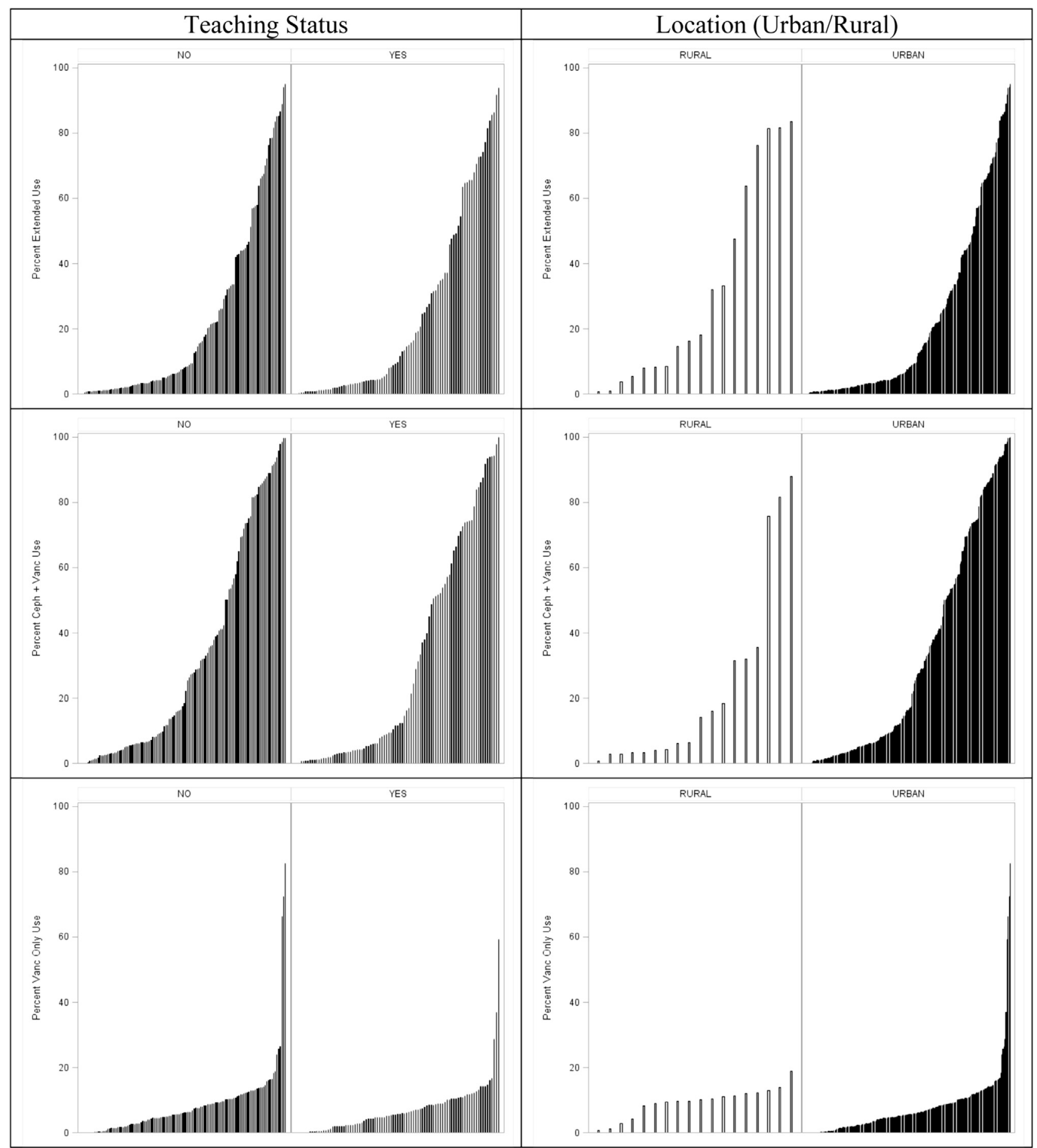

APPENDIX E3. Hospital variation in characteristics of antibiotic prophylaxis by hospital teaching status and location (urban vs rural). 